\title{
A test of the quasi-circumplex structure of human values
}

\author{
Amandine Perrinjaquet ${ }^{\mathrm{a}}$, Olivier Furrer ${ }^{\mathrm{b}}$, Jean-Claude Usunier ${ }^{\mathrm{a}, *}$, \\ Ghislaine Cestre $^{\mathrm{a}}$, Pierre Valette-Florence ${ }^{\mathrm{c}}$ \\ ${ }^{\text {a }}$ University of Lausanne, HEC, Switzerland \\ ${ }^{\mathrm{b}}$ Radboud University Nijmegen, Nijmegen School of Management, The Netherlands \\ ${ }^{\mathrm{c}}$ University of Grenoble, Graduate School of Business, France
}

Available online 4 January 2007

\begin{abstract}
Schwartz's value system (SVS) has been widely used in different disciplines (e.g., psychology, management, and marketing). Although the value structure seems to be validated when data are analyzed through multidimensional scaling, we show that the quasi-circumplex structure of human values is not supported when confirmatory analysis approaches (e.g., CIRCUM and constrained confirmatory factor analysis) are used. Based on two samples of French and Swiss respondents, confirmatory tests of SVS provide little support for its quasi-circumplex structure, mainly due to problems of construct and discriminant validity resulting from multicollinearity between value types.
\end{abstract}

(c) 2006 Elsevier Inc. All rights reserved.

Keywords: Human values; Circumplex structure; Schwartz value system; Psychometry; Multicollinearity; Constrained confirmatory factor analysis

\section{Introduction}

"Values are concepts or beliefs about desirable end states or behaviors that transcend specific situations, guide selection or evaluation of behavior and events, and are ordered by relative importance" (Schwartz \& Bilsky, 1987, p. 551). In the past two decades, individual values have been the focus of a wide range of studies, in particular those by Schwartz and

\footnotetext{
* Corresponding author. Fax: +41 216923495.

E-mail address: jean-claude.usunier@unil.ch (J.-C. Usunier).
} 
colleagues (e.g., Schwartz, 1992, 1994; Schwartz \& Bilsky, 1987, 1990; Schwartz \& Boehnke, 2004; Schwartz et al., 2001; Schwartz \& Sagiv, 1995). Building on Rokeach's (1973) work, Schwartz's value system (SVS) identifies 10 value types reflecting a continuum of related motivations: Self-direction, Stimulation, Hedonism, Achievement, Power, Security, Conformity, Tradition, Benevolence, and Universalism. This continuum is represented as a twodimensional, circular structure (see Fig. 1). The distribution of value types around the circle's circumference reflects their degree of congruence or conflict (Schwartz, 1992, 1994). The pursuit of particular values may conflict with actions intended to promote other values; for instance, the preservation of Tradition may conflict with the pursuit of novelty and change, related to Stimulation values. Conversely, some values may be congruent with others, such as Conformity and Tradition.

The structure and content of SVS have received empirical support, with over 200 samples from more than 60 countries (Schwartz, 1992, 1994; Schwartz et al., 2001; Schwartz \& Sagiv, 1995). SVS has been widely used in psychology (e.g., Feather, 1995; Wilson, 2005), international management (e.g., Egri \& Ralston, 2004; Ralston, Egri, Stewart, Terpstra, \& Yu, 1999), and marketing studies (e.g., Grunert \& Juhl, 1995; Steenkamp, ter Hofstede, \& Wedel, 1999), showing some predictive validity. However, a number of authors have questioned the psychometric properties of SVS, pointing out measurement and multicollinearity problems (e.g., Ben Slimane, El Akremi, \& Touzani, 2002; Burroughs \& Rindfleisch, 2002; Cable \& Edwards, 2004; Odin, Vinais, \& Valette-Florence, 1996; Olver \& Mooradian, 2003; Thøgersen \& Ölander, 2002).

Indeed, the structure of SVS has been shown to be nearly universal (Bardi \& Schwartz, 2003) mainly through multi-dimensional scaling (MDS), an exploratory rather than confirmatory data analysis method. As emphasized by Schwartz and Boehnke (2004, p. 230), "past support for the theory came from subjective judgments of visual plots of the relations among value items." As a consequence, Schwartz and Boehnke (2004) undertook constrained confirmatory factor analysis (CFA) and claimed to have confirmed the circular structure of human values in the form of a quasi-circumplex structure, representing a motivational continuum. However, their empirical findings were rather ambiguous and did not provide a fully convincing confirmation of the quasi-circumplex structure of SVS.

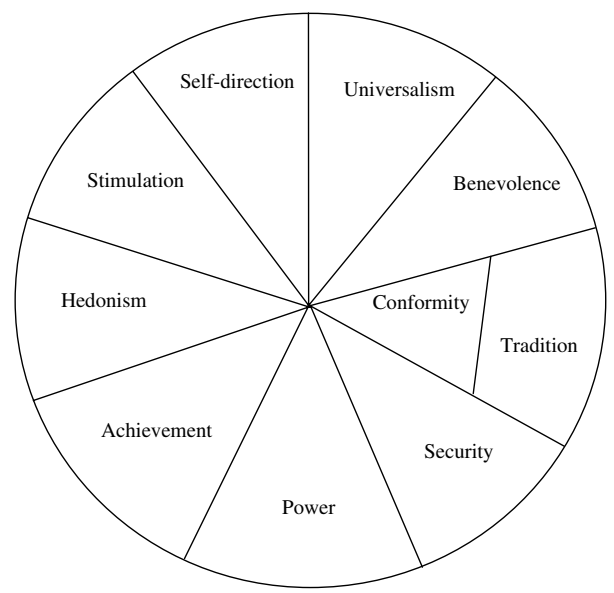

Fig. 1. Theoretical structural relations among the 10 value types (Adapted from Schwartz, 1992). 
Therefore, in a falsificationist perspective, this research replicates and refines the confirmatory approach of Schwartz and Boehnke (2004) by using two large samples of the Swiss and the French populations which conform to previous samples used in SVS research.

The structure of the paper is as follows: The first section reviews studies that verified SVS quasi-circumplex structure. The next section briefly presents the research instrument and sampling details. The third section follows the traditional MDS approach to SVS with an application to the French and the Swiss data collected for this research. The fourth and fifth sections present confirmatory analyses, respectively, using CIRCUM and constrained CFA. The last section discusses the findings.

\section{SVS and the circular structure}

The circular structure was formalized by Guttman (1954), under the term circumplex. A circumplex structure can represent either equally spaced variables (circulant model) or unequally spaced variables (quasi-circumplex model) on a circle's circumference. The higher-order (circulant) model is based on three assumptions: First, differences between variables can be reduced to differences in two dimensions (the circle, as a minimal representation); Second, all variables have equal projections (the constant radius property); Third, discrete variables are uniformly distributed around the circle (the equal spacing property) (Fabrigar, Visser, \& Browne, 1997; Gurtman, 1994; Larsen \& Diener, 1992). When equal spacing is relaxed but constant radius is maintained, the model is said to be quasi-circumplex (Guttman, 1954). In earlier works, Schwartz (1992) made no assumption as to whether value types are equally spaced or not. Visual inspection of plots from many national samples suggested, however, that both constant radius and equal spacing properties should be relaxed: Schwartz (1994) and Schwartz and Sagiv (1995) reported a peripheral location for Tradition and a central location for Conformity, at the same polar angle. Given these findings, Schwartz and Boehnke (2004) postulated that a "modified" quasi-circumplex model accounts more appropriately for such departures from circularity.

Tests of the quasi-circumplex structure of human values based on MDS and other exploratory techniques found visual support for Schwartz's value structure (e.g., Grunert \& Juhl, 1995; Kozan \& Ergin, 1999; Lindeman \& Verkasalo, 2005; Schwartz \& Bilsky, 1987, 1990; Spini \& Doise, 1998). Confirmatory tests have been conducted by Tsai and Böckenholt (2002) using Guttman's (1954) additive circumplex model based on the pairwise comparison of the 10 value types. The circular ordering of value types more or less followed the theory with the exception of Benevolence. However, results showed that even the least constrained model had a poor fit, and the factorial structure of the 56 items could not be tested due to the data collection method.

Brunsø, Scholderer, and Grunert (2004) developed another approach to test the circumplex structure, based on the assumption that the correlation between the 10 ordered value types and an external variable can be approximated by a quadratic model, which can then be tested using repeated-measures ANOVA. Some support was found for the circumplex structure, although only 30 of the 56 items were retained, and sum scores for the 10 value types were used despite fairly low reliability scores (average Cronbach alphas below .60). Moreover, a sinusoidal rather than quadratic function would have been more appropriate to formally test the circumplex structure (Gurtman, 1992; Schwartz, 1992; Wiggins, Steiger, \& Gaelick, 1981). 
SVS was rarely validated within a full confirmatory framework taking into account both measurement error and the circumplex nature of values. A notable exception can be found in Schwartz and Boehnke (2004) who used constrained CFA to test the quasi-circumplex structure. Despite encouraging results, the study had several limitations: (1) while CFAs confirmed the existence of 10 value types, some indices $\left(\chi^{2} / \mathrm{df}\right.$, RMSEA (Root Mean Square Error of Approximation)) indicated poor fit for most of the models being tested (Carmines \& McIver, 1981; Hu \& Bentler, 1999); (2) important CFA fit indices such as CFI (Comparative Fit Index), GFI (Goodness-of-Fit Index) or AGFI (Adjusted Goodness-ofFit Index) were not provided, making it difficult to conclusively assess the model; (3) many item loadings were below the recommended threshold of .60, indicating possible lack of construct reliability (Bagozzi \& Yi, 1988; Fornell \& Larcker, 1981); (4) while items with the lowest factor loadings were appropriately deleted, the fate of items with significant crossloadings was not addressed; finally (5) high correlations between adjacent values were reported (average correlation of .68), suggesting non-negligeable multicollinearity problems (Grewal, Cote, \& Baumgartner, 2004; Marsh, Dowson, Pietsch, \& Walker, 2004a). Based on the above account, it appears that further testing of SVS circumplex or quasi-circumplex structure is required.

\section{Research approach used to test SVS quasi-circumplex structure}

For the purpose of comparability with previous research, an item-base of 44 items was used (out of 56) that have been shown to emerge in predicted or adjacent locations in at least $75 \%$ of 97 samples from 44 countries (Oishi, Schimmack, Diener, \& Suh, 1998; Schwartz, 1994). MDS was first performed on the two national samples, namely Switzerland and France: visual inspection, as well as statistical indicators, show that the two data sets broadly fit with a quasi-circumplex structure. We then proceeded to use a confirmatory statistical technique for circular psychometric structures based on CIRCUM (Browne, 1992) which somewhat supported the quasi-circumplex structure for the two national samples. While values were properly ordered along the circle, angles between values differed from what is predicted by the theory. Since CIRCUM does not take into account measurement error at the item level, constrained CFA was used as in Schwartz and Boehnke (2004) following the same procedure, that is, with a reference matrix of expected factor intercorrelations. Using a large set of indicators for structural equations models, of which CFA is a particular case, the quasicircumplex structure of SVS is not supported for either France or Switzerland. The present analysis differs from that in Schwartz and Boehnke (2004) in that we do not use aggregate data sets across countries ( 27 countries in their study) as cross-national invariance theory recommends testing first for invariance of measurement instruments across national samples before comparing across countries or aggregating data sets (Steenkamp \& Baumgartner, 1998). The two national data sets are independently used in a falsificationist perspective, that is, in order to show that while visual inspection through MDS and CIRCUM supports SVS, a full scale confirmatory analysis taking into account measurement error does not.

\section{Samples and measurement}

The Swiss study was conducted in the French-speaking part of Switzerland. Survey data from self-administered questionnaires were collected from a sample of 1405 respondents. The female/male split was 40.0/60.0 and mean age was 29.9 (standard deviation $=12.7)$. The 
French sample (1891 respondents) is based on a representative survey of the French population conducted by SOFRES, a poll and market research company. The female/male split was 55.6/44.4 and mean age was 47.0 (standard deviation $=16.7$ ).

Individual values were measured with a French translation of the 56-value items SVS. ${ }^{1}$ The instructions and scoring procedures developed by Schwartz (Schwartz \& Sagiv, 1995) were followed: value items were presented in two lists representing terminal values (30 items) and instrumental values (26 items), with a short explanation for each item. Value items from different value types were presented in mixed order and measured on 9-point Likert scales ranging from "opposed to my values" [-1] through "important" [3] to "very important" [6] and "of supreme importance" [7] as guiding principles in life. Prior to rating the value items on each list, respondents were asked to choose and rate their most and least important values as anchoring points (Munson \& McIntyre, 1979).

\section{Multidimensional scaling}

Following Schwartz $(1992,1994)$ and Schwartz and Sagiv (1995), non metric MDS was used to compare the empirically derived circumplex structures of the SVS in the Swiss and French samples with the theoretical SVS structure. MDS is a data reduction method similar to factor analysis (Davison, 1983; Schiffman, Reynolds, \& Young, 1981) which helps to visualize the data structure. An overall assessment of the fit between theory and empirical data can be achieved using a "configurational verification" approach (Davison, 1983; Gurtman, 1994; Schwartz, 1992, 1994). MDS also helps to identify value items that are not located in their expected region (Feather, 1995; Grunert \& Juhl, 1995).

Two goodness-of-fit measures, stress index (Kruskal, 1964) and total variance accounted for (squared multiple correlation or RSQ) (Borg \& Lingoes, 1987), were used to check the interpretability of solutions. Schiffman et al. (1981) argue that RSQ is "the best indicator of how well the data fit the model" (p. 175). The empirical results for both the Swiss and the French samples for the two-dimensional solution postulated in Schwartz's theory are in line with earlier SVS test results (e.g., Grunert \& Juhl, 1995; Schwartz, 1992, 1994; Schwartz \& Sagiv, 1995). For the two-dimensional solution, stress is .25 in the Swiss sample and .20 in the French sample, which is comparable to the values reported by Schwartz (1992). ${ }^{2}$ RSQ is .65 in the Swiss sample and .78 in the French sample (RSQ coefficients were not reported by Schwartz).

To check whether this structure is similar to that postulated by Schwartz, boundary lines were set around spatial concentrations of value items for each value type, avoiding overlap between regions as much as possible (Lingoes, 1977, 1981), based on the same criteria as those proposed by Schwartz (1992, see p. 22 for details). Following Schwartz (1992), value types with overlapping items were combined, resulting in nine distinct regions in the Swiss sample: (1) Universalism, (2) Benevolence, (3) Tradition, (4) Conformity, (5) Security, (6) Power, (7) Achievement, (8) Stimulation and Hedonism, and (9) Self-direction. In the French sample, seven distinct regions emerged: (1) Universalism and Benevolence, (2) Tradition and Conformity, (3) Security, (4) Power, (5) Achievement, (6) Stimulation and Hedonism, and (7) Self-direction. In accordance with Schwartz's own criteria, all regions were confirmed.

\footnotetext{
${ }^{1}$ The 56-item version of the questionnaire was used because it remains the most widely used by researchers (e.g., Egri \& Ralston, 2004; Schultz et al., 2005).

${ }^{2}$ Schwartz (1992) reported stress coefficients ranging from .21 to .32 .
} 
Eleven percent of the value items ( 5 out of 44 ) were misplaced in the Swiss sample, i.e., they were found in regions other than expected. Three items (UN3 ( $A$ world of beauty), SD5 (Independent), TR4 (Respect for tradition)) were misplaced in adjacent regions and one (SE5 (Family security)) emerged in a more distant region. ${ }^{3}$ In the French sample, only $7 \%$ of the value items (3 out of 44) were misplaced. Two items (SE5 and SD5) were misplaced in an adjacent region and one (SD4 (Choosing own goals)) emerged in a more distant region.

To assess the ordering of the 10 value types, Schwartz (1992, p. 30-31) also developed a goodness-of-fit measure: the minimal number of single inversions in the ordering of adjacent value types (called "moves") that would be required to make the observed order match the ideal order. In the present study, one move is required to obtain the ideal order in the Swiss sample and two moves in the French sample. Results are comparable to those reported in the literature: the median number of moves of the 97 samples reported in Schwartz (1994) is 1.7 and 1.88 in the 88 samples reported in Schwartz and Sagiv (1995).

\section{Confirmatory factor analysis with CIRCUM}

The second step was to test the SVS structure using the CIRCUM software designed for circumplex models based on Fourier series correlation functions (Browne, 1992; Browne \& Cudeck, 1992). CIRCUM has been widely used to test circumplex data structures for personality and other psychological constructs (e.g., Acton \& Revelle, 2002; Ekkekakis, Hall, \& Petruzzello, 2005; Gurtman \& Pincus, 2000; Remington, Fabrigar, \& Visser, 2000; Strack, Choca, \& Gurtman, 2001). CIRCUM tests the circular structure consistent with most SVS research which averages value item scores to compute value type indices (e.g., Feather, 1995; Steenkamp et al., 1999). CIRCUM provides maximum likelihood (ML) parameter estimations and several goodness-of-fit indices. Unlike those provided by MDS, the CIRCUM fit indices are quite informative because the model tested corresponds to a circular representation of the data in which the distance between variables on the circle is a function of the correlation among them (Fabrigar et al., 1997).

Following the recommended procedure (e.g., Feather, 1995; Schwartz \& Sagiv, 1995), indices were computed for each of the 10 value types by averaging the scores of items retained from the MDS. Before computing the indices, error variances were estimated by computing their reliability (Bagozzi \& Edwards, 1998), resulting in $\alpha$ coefficients (Cronbach, 1951) ranging from .41 for Tradition $(\mathrm{CH})$ to .73 for Power $(\mathrm{CH})(\mathrm{UN}=.66(\mathrm{CH})$, $.71(\mathrm{~F}) ; \mathrm{BE}=.67(\mathrm{CH}), .72(\mathrm{~F}) ; \mathrm{TR}=.41(\mathrm{CH}), .52(\mathrm{~F}) ; \mathrm{CO}=.67(\mathrm{CH}), .69(\mathrm{~F}) ; \mathrm{SE}=.60(\mathrm{CH})$, $.64(\mathrm{~F}) ; \mathrm{AC}=.63(\mathrm{CH}), .71(\mathrm{~F}) ; \mathrm{PO}=.73(\mathrm{CH}), .70(\mathrm{~F}) ; \mathrm{HE}=.58(\mathrm{CH}), .66(\mathrm{~F}) ; \mathrm{ST}=.72(\mathrm{CH})$, $.71(\mathrm{~F}) ; \mathrm{SD}=.57(\mathrm{CH}), .58(\mathrm{~F}))$. The generally accepted threshold for Cronbach's $\alpha$ is .70 (Nunnally, 1978; Robinson, Shaver, \& Wrightsman, 1991). While indicating a relatively weak reliability for two value types (Tradition and Self-direction), $\alpha$ coefficients show that value items share enough common variance to justify averaging value items.

The equal spacing-equal communalities (circulant) model was first tested (Model A). The equal spacing constraint (variables are uniformly distributed around the circle) was then relaxed (Model B). Finally, both constraints were relaxed (i.e., angles and distances to the circle center were set free in Model C). A three-component model $(m=3)$ was specified in CIRCUM; it is the least restrictive and most widely used model for testing circumplex

3 TR3 (Humble) was completely misplaced so that further analysis was done on a 43-item base. 
Table 1

Summary of CIRCUM fit indices for the Swiss and the French samples

\begin{tabular}{|c|c|c|c|c|c|c|}
\hline Model & $\mathrm{df}$ & $\chi^{2}$ & $F_{0}$ & GFI & AGFI & RMSEA $[90 \% \mathrm{CI}]$ \\
\hline \multicolumn{7}{|c|}{ A. Equally spaced-equal communalities } \\
\hline Switzerland & 41 & 667.23 & .446 & .918 & .890 & $.104[.097, .111]$ \\
\hline France & 41 & 1055.09 & .537 & .903 & .870 & $.114[.108, .120]$ \\
\hline \multicolumn{7}{|c|}{ B. Unequally spaced-equal communalities } \\
\hline Switzerland & 32 & 503.79 & .336 & .937 & .892 & $.102[.095, .110]$ \\
\hline France & 32 & 750.93 & .380 & .929 & .879 & $.109[.102, .116]$ \\
\hline \multicolumn{7}{|c|}{ C. Unequally spaced-unequal communalities } \\
\hline Switzerland & 23 & 280.76 & .184 & .964 & .915 & $.089[.080, .099]$ \\
\hline France & 23 & 513.59 & .260 & .951 & .882 & $.106[.098, .114]$ \\
\hline
\end{tabular}

structures (Browne, 1992). Additional free parameters did not improve the model fit. Consistent with common practice (Byrne, 2001; Hu \& Bentler, 1999), multiple indices were used to estimate model fit, including (1) $\chi^{2}$ likelihood ratio; (2) $F_{0}$, the maximum likelihood discrepancy function, a measure of absolute fit; (3) GFI (Jöreskog \& Sörbom, 1986), which is analogous to a squared multiple correlation; (4) AGFI (Jöreskog \& Sörbom, 1986), a parsimony weighted measure of model fit (both GFI and AGFI were computed from formulas presented in Maiti \& Mukherjee, 1990); and (5) RMSEA (Browne \& Cudeck, 1992; Steiger \& Lind, 1980), also a parsimony weighted measure of model fit. Results are consistent with those of Tsai and Böckenholt (2002), who tested the SVS circumplex structure using Guttman's (1954) additive model, which is comparable to the Fourier series correlation functions used by CIRCUM (Browne, 1992).

Table 1 presents fit indices for the three different models for the Swiss and French samples. The highly constrained model (Model A) does not fit the data very well. While GFI is above the conventional threshold for both samples (>.90), AGFI is lower than .90 , indicating a lack of parsimony due to the constraints (Hu \& Bentler, 1999). RMSEAs are too high $(\mathrm{CH}=.104 ; F=.114){ }^{4}$ Removing the equal-spacing constraint (quasi-circumplex model B) leads to an improvement in model fit, however with RMSEAs still too high $(\mathrm{CH}=.102$; $F=.109$ ). Finally, relaxing the equal communalities constraints (Model C) further improves model fit, however still with relatively high $\mathrm{RMSEAs}(\mathrm{CH}=.089 ; F=.106)$.

Goodness-of-fit indices do not provide information as to whether the actual locations of values are consistent with Schwartz's theoretical model. The extent to which value locations depart from the equally spaced and/or equal communalities model has to be established. Fig. 2 displays three circular representations for each national data set: circulant (fully constrained Model A), communalities constrained to equality with unconstrained polar angles (Model B), and unequally spaced - unequal communalities (unconstrained model C). Other useful pieces of information provided by CIRCUM are communality indices and polar angles of the measured variables. These indices represent the correlation between each measured variable and its common score (Fabrigar et al., 1997). When squared, the communality indices represent the amount of common variance in each measured variable. Estimates in Tables 2 and 3 point to measurement error in the 10 value types.

\footnotetext{
${ }^{4}$ Browne and Cudeck (1992) suggest that RMSEA should ideally be below .05, acceptably below .08 and that coefficients greater than .10 constitute poor model fit. However, using simulations, Hu and Bentler (1999) show that when using a cutoff point of .07 or .08 , RMSEA substantially underrejects misspecified models.
} 


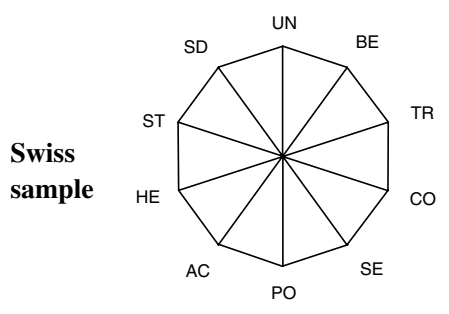

Model A
Equally spaced-equal communalities

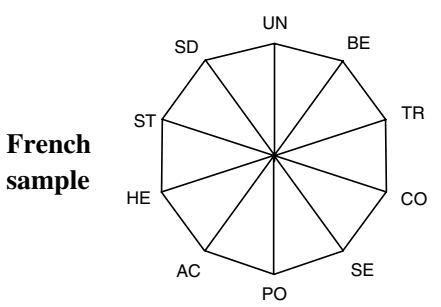

Model A

Equally spaced-equal communalities

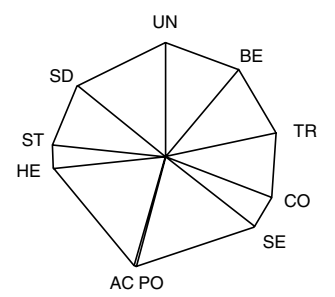

Model B

Unequally spaced-equal communalities

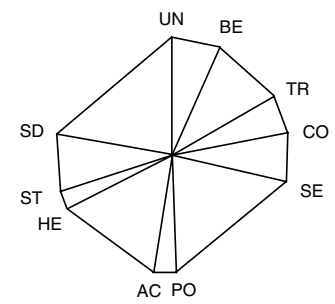

Model B

Unequally spaced-equal communalities

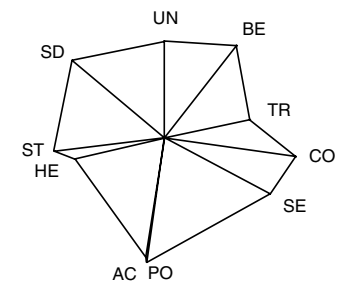

Model C

Unequally spaced-unequal communalities

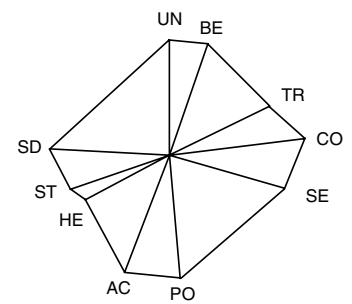

Model C

Unequally spaced-unequal communalities

Fig. 2. French and Swiss CIRCUM results.

Table 2

CIRCUM point estimates for polar angles and communality indices for the Swiss sample

\begin{tabular}{|c|c|c|c|c|c|c|c|c|c|c|}
\hline Model & $\mathrm{UN}$ & $\mathrm{BE}$ & TR & $\mathrm{CO}$ & SE & $\mathrm{PO}$ & $\mathrm{AC}$ & $\mathrm{HE}$ & ST & SD \\
\hline \multicolumn{11}{|c|}{ A. Equally spaced-equal communalities } \\
\hline Polar angles & 0 & 36 & 72 & 108 & 144 & 180 & 216 & 252 & 288 & 324 \\
\hline Communalities & .70 & .70 & .70 & .70 & .70 & .70 & .70 & .70 & .70 & .70 \\
\hline \multicolumn{11}{|c|}{ B. Unequally spaced-equal communalities } \\
\hline Polar angles & 0 & 40 & 78 & 111 & 128 & 195 & 196 & 264 & 276 & 309 \\
\hline Communalities & .72 & .72 & .72 & .72 & .72 & .72 & .72 & .72 & .72 & .72 \\
\hline \multicolumn{11}{|c|}{ C. Unequally spaced-unequal communalities } \\
\hline Polar angles & 0 & 38 & 78 & 98 & 118 & 188 & 189 & 257 & 263 & 310 \\
\hline Communalities & .62 & .75 & .56 & .85 & .76 & .80 & .76 & .59 & .71 & .77 \\
\hline
\end{tabular}

In Fig. 2, Universalism was used as the reference variable (location set at $0^{\circ}$ ). Deviations from the ideal model are consistent with those of the MDS results, where Achievement and Power already formed a joint domain. Two domains from the MDS, Stimulation and Hedonism $\left(\mathrm{CH}=6^{\circ} ; F=9^{\circ}\right)$ are also closer than postulated by a circumplex structure, that is, equally spaced (see Tables 2 and 3 ).

Fig. 2 shows that the ordering of values is consistent with Schwartz's theory. However, the differences between the angles of the two unequally spaced models (B and C) and those of the equally spaced model A are relatively important. In the unequally spaced-unequal communalities representation (Model C), Achievement and Power are near each other in the Swiss data $\left(1^{\circ}\right)$ while Stimulation and Hedonism $\left(9^{\circ}\right)$ are close in the French data. On the other hand, Tradition and Conformity are clearly separate from one another for both countries $\left(\mathrm{CH}=20^{\circ} ; F=19^{\circ}\right)$. This contradicts the "definitive" model proposed 
Table 3

CIRCUM point estimates for polar angles and communality indices for the French sample

\begin{tabular}{|c|c|c|c|c|c|c|c|c|c|c|}
\hline Model & UN & $\mathrm{BE}$ & TR & $\mathrm{CO}$ & $\mathrm{SE}$ & $\mathrm{PO}$ & $\mathrm{AC}$ & $\mathrm{HE}$ & ST & SD \\
\hline \multicolumn{11}{|c|}{ A. Equally spaced-equal communalities } \\
\hline Polar angles & 0 & 36 & 72 & 108 & 144 & 180 & 216 & 252 & 288 & 324 \\
\hline Communalities & .75 & .75 & .75 & .75 & .75 & .75 & .75 & .75 & .75 & .75 \\
\hline \multicolumn{11}{|c|}{ B. Unequally spaced-equal communalities } \\
\hline Polar angles & 0 & 24 & 60 & 79 & 103 & 178 & 189 & 243 & 252 & 280 \\
\hline Communalities & .75 & .75 & .75 & .75 & .75 & .75 & .75 & .75 & .75 & .75 \\
\hline \multicolumn{11}{|c|}{ C. Unequally spaced-unequal communalities } \\
\hline Polar angles & 0 & 19 & 64 & 83 & 106 & 175 & 201 & 242 & 251 & 273 \\
\hline Communalities & .73 & .75 & .71 & .87 & .76 & .79 & .80 & 61 & 67 & .76 \\
\hline
\end{tabular}

by Schwartz (1992) and tested by Schwartz and Boehnke (2004), hypothesizing that these values should be located at the same polar angle.

\section{Constrained CFA}

CIRCUM does not take into account measurement error of the individual manifest variables, treating error variances as known parameters rather than unknown values to be statistically estimated (Bagozzi \& Edwards, 1998; Kenny \& McCoach, 2003). The use of structural equation modeling to test circumplex models was first proposed by Jöreskog (1974) and applied by Wiggins et al. (1981). In this study, AMOS 4.0 (Arbuckle \& Wothke, 1999) and maximum likelihood (ML) estimation were used for all models. ML estimation was used because of its robustness when the data deviate from multivariate normality (Browne \& Shapiro, 1988; McDonald \& Ho, 2002).

As in Schwartz and Boehnke (2004), constrained CFA was used to test the quasi-circumplex structure for latent variables together with the simple factorial structure for manifest variables (see Gaines et al., 1997; Tracey, 2000; Wiggins et al., 1981) by specifying a reference matrix of expected value correlations and by testing the fit of the reference matrix to the observed data (Jöreskog, 1974, 1978). We used two different reference matrices to test empirical circulant models $\mathrm{D}$ and $\mathrm{E}$, and another reference matrix for the test of the quasi-circumplex model F. First, a reference matrix based on the data-driven approach used by Schwartz and Boehnke (2004) was specified to test the empirical circulant model D. ${ }^{5}$ The average intercorrelation was computed on both samples, yielding a maximum reference correlation between adjacent values of .69 for

\footnotetext{
${ }^{5}$ As discussed in Gurtman (2001), different measures can be used to compute the expected intercorrelations between all pairs of values for this circulant model, assuming that they are a monotonic function of angular discrepancy between pairs of values. Earlier papers by Gurtman and colleagues (Gurtman, 1992, 1993, 1994; Pincus, Gurtman, \& Ruiz, 1998) propose the cosine difference (already used by Wiggins et al., 1981) as an indicator of circular correlation: it has the desirable property of ranging from -1 to +1 . This measure was also used by Gaines et al. (1997) to test the circumplexity of interpersonal traits using constrained CFA. It is a special case of the Fourier series correlation function used in CIRCUM (Browne, 1992; Fabrigar et al., 1997). However, as noted by Gurtman (2001), it is not linearly related to angular discrepancy throughout its continuum. Therefore, following Schwartz and Boehnke (2004), Gurtman's (2001) $A$ statistic was used to compute the expected intercorrelations between all pairs of values, with $A=(90-D) / 90$, where $D$ is the angular discrepancy in degrees. $A$ is proportional (Wagner, Kiesler, $\&$ Schmidt, 1995) and nearly coincides with the cosine correlation throughout much of its range (Gurtman, 2001).
} 
Table 4

Reference matrices of expected factor intercorrelations for CFA on the Swiss sample

\begin{tabular}{lrrrrrrrrrr}
\hline Value type & UN & \multicolumn{1}{c}{ BE } & \multicolumn{1}{c}{ TR } & CO & SE & PO & AC & HE & ST & SD \\
\hline Universalism (UN) & $\mathbf{1 . 0 0}$ & .90 & .71 & .51 & .32 & .22 & .32 & .51 & .71 & .90 \\
Benevolence (BE) & .85 & $\mathbf{1 . 0 0}$ & .90 & .71 & .51 & .32 & .22 & .32 & .51 & .71 \\
Tradition (TR) & .63 & .87 & $\mathbf{1 . 0 0}$ & .90 & .71 & .51 & .32 & .22 & .32 & .51 \\
Conformity (CO) & .47 & .67 & .90 & $\mathbf{1 . 0 0}$ & .90 & .71 & .51 & .32 & .22 & .32 \\
Security (SE) & .38 & .59 & .79 & .97 & $\mathbf{1 . 0 0}$ & .90 & .71 & .51 & .32 & .22 \\
Power (PO) & .21 & .24 & .44 & .60 & .69 & $\mathbf{1 . 0 0}$ & .90 & .71 & .51 & .32 \\
Achievement (AC) & .21 & .24 & .44 & .60 & .69 & 1.00 & $\mathbf{1 . 0 0}$ & .90 & .71 & .51 \\
Hedonism (HE) & .55 & .34 & .19 & .25 & .34 & .68 & .69 & $\mathbf{1 . 0 0}$ & .90 & .71 \\
Stimulation (ST) & .61 & .40 & .22 & .21 & .27 & .62 & .63 & .98 & $\mathbf{1 . 0 0}$ & .90 \\
Self-Direction (SD) & .79 & .57 & .38 & .22 & .19 & .46 & .46 & .82 & .89 & $\mathbf{1 . 0 0}$ \\
\hline ClR CUM-bas
\end{tabular}

CIRCUM-based empirical circulant model above the diagonal and CIRCUM-based quasi-circumplex model below the diagonal.

Table 5

Reference matrices of expected factor intercorrelations for CFA on the French sample

\begin{tabular}{lrrrrrrrrrr}
\hline Value type & UN & \multicolumn{1}{c}{ BE } & \multicolumn{1}{c}{ TR } & CO & SE & PO & AC & HE & ST & SD \\
\hline Universalism (UN) & $\mathbf{1 . 0 0}$ & .92 & .74 & .54 & .38 & .31 & .38 & .54 & .74 & .92 \\
Benevolence (BE) & .95 & $\mathbf{1 . 0 0}$ & .92 & .74 & .54 & .38 & .31 & .32 & .54 & .74 \\
Tradition (TR) & .78 & .91 & $\mathbf{1 . 0 0}$ & .92 & .74 & .54 & .38 & .31 & .32 & .54 \\
Conformity (CO) & .69 & .81 & .97 & $\mathbf{1 . 0 0}$ & .92 & .74 & .54 & .38 & .31 & .32 \\
Security (SE) & .58 & .69 & .87 & .96 & $\mathbf{1 . 0 0}$ & .92 & .74 & .54 & .38 & .31 \\
Power (PO) & .29 & .34 & .51 & .60 & .71 & $\mathbf{1 . 0 0}$ & .92 & .74 & .54 & .38 \\
Achievement (AC) & .30 & .31 & .45 & .54 & .65 & .99 & $\mathbf{1 . 0 0}$ & .92 & .74 & .54 \\
Hedonism (HE) & .51 & .39 & .29 & .31 & .40 & .76 & .82 & $\mathbf{1 . 0 0}$ & .92 & .74 \\
Stimulation (ST) & .55 & .44 & .30 & .30 & .36 & .71 & .77 & .99 & $\mathbf{1 . 0 0}$ & .92 \\
Self-Direction (SD) & .68 & .57 & .40 & .32 & .29 & .58 & .63 & .90 & .94 & $\mathbf{1 . 0 0}$ \\
\hline
\end{tabular}

CIRCUM-based empirical circulant model above the diagonal and CIRCUM-based quasi-circumplex model below the diagonal.

the Swiss sample and of .75 for the French sample. The same procedure was applied to all pairs of opposing values, resulting in a minimum reference correlation of 16 for the Swiss sample and of .29 for the French sample. Distances between pairs of values were then computed by dividing the difference between the maximum and the minimum correlations into five increments, yielding the following reference correlations: $.56, .43$, and .29 for the Swiss sample and .64, .52, and .41 for the French sample.

A second reference matrix was derived from the output correlation matrix of CIRCUM equally spaced-equal communalities model to test Model E. Indeed, CIRCUM was shown to provide a better estimation of intercorrelation between all pairs of values than Schwartz and Boehnke's (2004) method for computing the reference matrix (see Fabrigar et al., 1997). CIRCUM also allows for the estimation of reference matrices for quasi-circumplex models with unequal spacing. Therefore, we also used a third reference matrix based on the output correlation matrix from CIRCUM unequally spaced-equal communalities model to test the quasi-circumplex model $\mathrm{F}$ (see Tables 4 and 5).

To test models D and E, correlations between value types were constrained, based on the reference matrices in order to ensure equal spacing. For model F (quasi-circumplex), correlations between value types were constrained based on the reference matrix from 
CIRCUM. For all three models, the variances of the value types were also constrained to 1 to ensure equal communalities. Ridge estimation was used (Gaines et al., 1997; Jöreskog \& Sörbom, 1989; Wothke, 1993) when the covariance matrix was non-positive definite due to the constraints imposed. This was the case for the models based on CIRCUM reference matrices. Ridge estimation introduces a small bias (marginally affecting the $\chi^{2}$ of the model as well as other fit indices such as GFI) in return for greater efficiency (Grewal et al., 2004). A ridge constant of .01 was specified for all models, which is small enough to minimize its biasing effect on model fit indices (McQuitty, 1997).

\subsection{Assessing model fit}

The same indices as those reported by Schwartz and Boehnke (2004) were first computed: $\chi^{2}$ and $\chi^{2} / \mathrm{df}$ statistics, Standardized Root Mean Squared Residuals (SRMR), RMSEA, and Akaike Information Criterion (AIC). Several other important fit indices, omitted by Schwartz and Boehnke (2004), are reported in Table 6: GFI, AGFI, Normed Fit Index (NFI, Bentler, 1990), Non-Normed Fit Index (NNFI $\left.{ }^{6}\right)$, and CFI. A large array of model fit indices is necessary since some of them may be biased (MacCallum \& Austin, 2000; Marsh, Hau, \& Wen, 2004b) ${ }^{7}$.

The quasi-circumplex model provides better levels of fit than the empirical circulant models for both national samples. However, $\chi^{2} / \mathrm{df}$ ranges from 5.85 to 8.64 (whereas it should be below the conventional cutoff point of 3; Carmines \& McIver, 1981); GFI and AGFI range from .80 to .83 and comparative fit indices, CFI, NFI and NNFI, range from .67 to .74, when they should always be above .90. All AIC values are larger than 5204.7, providing additional evidence of inadequate levels of fit. RMSEAs and SRMRs seem to be acceptable with values between .059 and .064 (RMSEA), and between .068 and .076 $(\mathrm{SRMR})^{8}$ consistent with values reported by Schwartz and Boehnke. However, RMSEA and SRMR are biased downwards with the number of items and variables in a model (Anderson \& Gerbing, 1984; Breivik \& Olsson, 2001; Kenny \& McCoach, 2003). Because SVS has a relatively large number of variables and items, RMSEAs and SRMRs are underestimated, erroneously causing model acceptance. On the other hand, GFI and AGFI increase (i.e., artificially improve) with sample size but are relatively stable as the number of items and variables in the model increase (Fan, Thompson, \& Wang, 1999; Hu \& Bentler, 1999; Kenny \& McCoach, 2003). Since sample size is large in the data sets, GFIs and AGFIs are biased upward. Despite this "favorable" bias which tends to inflate their value, all GFIs and AGFIs remain below minimum recommended thresholds (.90 for GFI and AGFI; Hu \& Bentler, 1999). Finally, comparative fit indices, CFI (with a conventional cutoff point at .95), NFI and NNFI (both with a conventional cutoff point at .90) have been shown to be robust to sample size (Fan et al., 1999; Hu \& Bentler, 1998) and number of items and variables (Anderson \& Gerbing, 1984; Kenny \& McCoach, 2003). They are all well below acceptability with an average level of .70 .

\footnotetext{
${ }^{6}$ NNFI (Bentler \& Bonett, 1980) is also known as the Tucker-Lewis Index (TLI) (Tucker \& Lewis, 1973).

7 Four factors have been shown to have a biasing effect on fit indices: the number of latent variables and items, sample size, the use of a ridge constant, and the level of multicollinearity between the variables.

8 The recommended maximum threshold for SRMR is .08 (Browne \& Cudeck, 1992; Hu \& Bentler, 1999).
} 
Table 6

Fit indices for the different CFA models estimated with AMOS

\begin{tabular}{|c|c|c|c|c|c|c|c|c|c|c|c|}
\hline & $\mathrm{df}$ & $\chi^{2}$ & $\chi^{2} / \mathrm{df}$ & GFI & AGFI & RMSEA [ $90 \% \mathrm{CI}]$ & SRMR & CFI & NFI & NNFI & AIC \\
\hline \multicolumn{12}{|c|}{$\begin{array}{l}\text { D. Empirical circulant model } 1^{\mathrm{a}} \\
\text { (equally spaced-equal communalities) }\end{array}$} \\
\hline Switzerland & 860 & 5096.5 & 5.926 & .830 & .813 & $.059[.058, .061]$ & .071 & .719 & .681 & .705 & 5268.5 \\
\hline France & 860 & 7106.8 & 8.263 & .832 & .815 & $.062[.061, .063]$ & .076 & .740 & .715 & .727 & 7278.8 \\
\hline \multicolumn{12}{|c|}{$\begin{array}{l}\text { E. Empirical circulant model } 2^{\mathrm{b}} \\
\text { (equally spaced-equal communalities) }\end{array}$} \\
\hline Switzerland & 860 & 5356.9 & 6.229 & .819 & .801 & $.061[.059, .063]$ & .071 & .702 & .665 & .687 & 5528.9 \\
\hline France & 860 & 7431.4 & 8.641 & .820 & .802 & $.064[.062, .065]$ & .075 & .727 & .702 & .713 & 7603.4 \\
\hline \multicolumn{12}{|c|}{$\begin{array}{l}\text { F. Quasi-circumplex model } \\
\text { (unequally spaced-equal communalities) }\end{array}$} \\
\hline Switzerland & 860 & 5032.7 & 5.852 & .829 & .811 & $.059[.057, .060]$ & .068 & .723 & .685 & .709 & 5204.7 \\
\hline France & 860 & 7023.9 & 8.167 & .829 & .812 & $.062[.060, .063]$ & .068 & .744 & .719 & .731 & 7195.9 \\
\hline
\end{tabular}

${ }^{a}$ Reference matrix based on Schwartz and Boehnke (2004).

b Reference matrix based on the output correlation matrix from CIRCUM. 


\subsection{Multicollinearity tests}

High correlations between adjacent value types specified in reference matrices suggest potential problems of multicollinearity (Grewal et al., 2004; Jagpal, 1982; Marsh et al., 2004a). To check for multicollinearity, we examined conditioning indices and variancedecomposition proportions associated with each value type (Belsley, Kuh, \& Welsch, 1980). Too large a conditioning index (i.e., a value greater than 10 to 30 depending on the data) and at least two variance-decomposition proportions larger than .50 in the case of only one near dependency, or the sum of the variance-decomposition proportions greater than .50 in the case of several near dependencies indicate multicollinearity (Belsley, 1991). In the Swiss sample, six conditioning indices exceeding 40 and 18 exceeding 30 and the variance-decomposition proportions indicated that there was high multicollinearity, especially between Benevolence and Self-direction, between Power, Achievement and Self-direction, as well as between Conservation and Security. A close examination of conditioning indices and variance-decomposition proportions at value-item level showed that multicollinearity problems were mainly due to the following two groups of items: (1) BE5 (Responsible), AC2 (Capable), SD3 (Freedom), BE4 (Loyal), BE2 (Honest), SD4 (Choosing own goals), and SE4 (Social order); and (2) SE5 (Family security) and CO2 (Honoring of parents and elders). In the French sample, three conditioning indices were particularly large. An examination of variance-decomposition proportions showed that the most important multicollinearity problems were between Benevolence, Universalism, Power, and Achievement, between Conservation and Security, as well as between Self-direction, Universalism, and Security. High multicollinearity occurred with the same items for the French and the Swiss sample except UN4 (Broad-minded) and UN5 (Social justice) which were the cause in the French data only.

\subsection{Construct reliability and discriminant validity}

Because of high levels of multicollinearity, construct reliability and validity as well as discriminant validity of SVS had to be assessed. All value items significantly loaded on the hypothesized factor. However, 34 items in the Swiss sample and 30 items in the French sample (out of 43 items) did not reach the .60 loading threshold recommended by Bagozzi and Yi (1988) to ensure construct reliability. Construct reliability of value types was further assessed using coefficient $\alpha$ (Cronbach, 1951) and coefficient rhô (Jöreskog, 1971). In each sample, all but two coefficients (those of Power and Stimulation in the Swiss sample and those of Universalism and Conservation in the French sample) failed to reach the recommended .70 level (Fornell \& Larcker, 1981; Nunnally, 1978; Ping, 2004). A test to assess construct validity was conducted by examining the average variance extracted (AVE) for each value type (Fornell \& Larcker, 1981; Ping, 2004). None of the AVE reached the recommended level of .50 (Fornell \& Larcker, 1981 ) indicating the lack of convergent validity for SVS in both samples (see Tables 7 and 8).

Multicollinearity is closely related to discriminant validity (Grewal et al., 2004): if items are too highly correlated across value types, the instrument lacks discriminant validity. To test the discriminant validity of value types, shared variance (squared correlation) between pairs of constructs was compared with the corresponding AVE (Fornell \& Larcker, 1981). Twenty-seven value types out of 45 possible pairs $(60 \%)$ in 
Table 7

Constrained confirmatory factor analysis results for the Swiss sample

\begin{tabular}{|c|c|c|c|c|c|c|}
\hline Value type & Value item & Standardized loading & $t$-value & $\alpha$ & $\mathrm{CR}$ & AVE \\
\hline \multirow[t]{5}{*}{ UN } & UN1 & .555 & 20.506 & \multirow[t]{5}{*}{.662} & \multirow[t]{5}{*}{.635} & \multirow[t]{5}{*}{.261} \\
\hline & UN2 & .544 & 20.044 & & & \\
\hline & UN3 & .397 & 14.000 & & & \\
\hline & UN4 & .491 & 17.776 & & & \\
\hline & UN5 & .550 & 20.278 & & & \\
\hline \multirow[t]{5}{*}{$\mathrm{BE}$} & BE1 & .635 & 24.151 & \multirow[t]{5}{*}{.668} & \multirow[t]{5}{*}{.651} & \multirow[t]{5}{*}{.275} \\
\hline & BE2 & .509 & 18.482 & & & \\
\hline & BE3 & .523 & 19.065 & & & \\
\hline & BE4 & .478 & 17.197 & & & \\
\hline & BE5 & .458 & 16.355 & & & \\
\hline \multirow[t]{4}{*}{ TR } & TR1 & .256 & 8.727 & \multirow[t]{4}{*}{.411} & \multirow[t]{4}{*}{.371} & \multirow[t]{4}{*}{.133} \\
\hline & TR2 & .366 & 12.726 & & & \\
\hline & TR4 & .462 & 16.441 & & & \\
\hline & TR5 & .345 & 11.961 & & & \\
\hline \multirow[t]{4}{*}{$\mathrm{CO}$} & $\mathrm{CO} 1$ & .641 & 25.261 & \multirow[t]{4}{*}{.667} & \multirow[t]{4}{*}{.679} & \multirow[t]{4}{*}{.348} \\
\hline & $\mathrm{CO} 2$ & .587 & 22.588 & & & \\
\hline & $\mathrm{CO} 3$ & .612 & 23.798 & & & \\
\hline & $\mathrm{CO} 4$ & .511 & 19.067 & & & \\
\hline \multirow{5}{*}{$\mathrm{SE}$} & SE1 & .580 & 22.070 & \multirow[t]{5}{*}{.599} & \multirow[t]{5}{*}{.605} & \multirow[t]{5}{*}{.237} \\
\hline & SE2 & .483 & 17.752 & & & \\
\hline & SE3 & .441 & 15.979 & & & \\
\hline & SE4 & .515 & 19.119 & & & \\
\hline & SE5 & .396 & 14.167 & & & \\
\hline \multirow[t]{5}{*}{ PO } & PO1 & .539 & 20.535 & \multirow[t]{5}{*}{.734} & .719 & .339 \\
\hline & $\mathrm{PO} 2$ & .603 & 23.643 & & & \\
\hline & PO3 & .594 & 23.169 & & & \\
\hline & $\mathrm{PO} 4$ & .595 & 23.222 & & & \\
\hline & PO5 & .576 & 22.288 & & & \\
\hline $\mathrm{AC}$ & $\mathrm{ACl}$ & .560 & 21.544 & .632 & .624 & .262 \\
\hline & $\mathrm{AC} 2$ & .431 & 15.864 & & & \\
\hline & $\mathrm{AC} 3$ & .636 & 25.333 & & & \\
\hline & $\mathrm{AC} 4$ & .582 & 22.627 & & & \\
\hline & AC5 & .263 & 9.315 & & & \\
\hline HE & HE1 & .557 & 20.771 & .575 & .447 & .288 \\
\hline & HE2 & .516 & 18.976 & & & \\
\hline ST & ST1 & .614 & 23.892 & .717 & .707 & .447 \\
\hline & ST2 & .677 & 27.179 & & & \\
\hline & ST3 & .711 & 29.034 & & & \\
\hline SD & SD1 & .594 & 22.525 & .570 & .595 & .238 \\
\hline & SD2 & .610 & 23.286 & & & \\
\hline & SD3 & .418 & 14.937 & & & \\
\hline & SD4 & .458 & 16.556 & & & \\
\hline & SD5 & .286 & 9.922 & & & \\
\hline Model Fit Indices & $\chi^{2}=5032.65$ & $000), \mathrm{df}=860, \chi^{2} / \mathrm{df}=5$ & & & & \\
\hline & $\mathrm{SRMR}=.06$ & $\mathrm{I}=.829, \mathrm{AGFI}=.811, \mathrm{C}$ & & & & \\
\hline & RMSEA $=$ & $\%$ CI of .057 to .060$]$ & & & & \\
\hline & $\mathrm{AIC}=5204$. & $\mathrm{FI}=.685$ & & & & \\
\hline
\end{tabular}

Note. CR, Construct Reliability; AVE, Average Variance Extracted; $\alpha$, Cronbach's alpha. -1, opposed to my values; 7, of supreme importance. 
Table 8

Constrained confirmatory factor analysis results for the French sample

\begin{tabular}{|c|c|c|c|c|c|c|}
\hline Value type & Value item & Standardized loading & $t$-value & $\alpha$ & $\mathrm{CR}$ & AVE \\
\hline \multirow[t]{5}{*}{ UN } & UN1 & .609 & 27.676 & \multirow[t]{5}{*}{.709} & \multirow[t]{5}{*}{.701} & \multirow[t]{5}{*}{.322} \\
\hline & UN2 & .613 & 27.909 & & & \\
\hline & UN3 & .603 & 27.288 & & & \\
\hline & UN4 & .441 & 18.802 & & & \\
\hline & UN5 & .552 & 24.463 & & & \\
\hline \multirow[t]{5}{*}{$\mathrm{BE}$} & BE1 & .630 & 29.213 & \multirow[t]{5}{*}{.719} & \multirow[t]{5}{*}{.690} & \multirow[t]{5}{*}{.310} \\
\hline & BE2 & .569 & 25.657 & & & \\
\hline & BE3 & .551 & 24.658 & & & \\
\hline & BE4 & .504 & 22.142 & & & \\
\hline & BE5 & .520 & 22.988 & & & \\
\hline \multirow[t]{4}{*}{ TR } & TR1 & .514 & 22.644 & \multirow[t]{4}{*}{.519} & \multirow[t]{4}{*}{.517} & \multirow[t]{4}{*}{.217} \\
\hline & TR2 & .369 & 15.582 & & & \\
\hline & TR4 & .564 & 25.344 & & & \\
\hline & TR5 & .385 & 16.293 & & & \\
\hline \multirow[t]{4}{*}{$\mathrm{CO}$} & $\mathrm{CO} 1$ & .641 & 30.147 & \multirow[t]{4}{*}{.693} & \multirow[t]{4}{*}{.702} & \multirow[t]{4}{*}{.372} \\
\hline & $\mathrm{CO} 2$ & .625 & 29.127 & & & \\
\hline & $\mathrm{CO} 3$ & .640 & 30.049 & & & \\
\hline & $\mathrm{CO} 4$ & .528 & 23.547 & & & \\
\hline \multirow[t]{5}{*}{ SE } & SE1 & .560 & 24.867 & \multirow{5}{*}{.638} & \multirow[t]{5}{*}{.644} & \multirow[t]{5}{*}{.268} \\
\hline & SE2 & .568 & 25.276 & & & \\
\hline & SE3 & .443 & 18.869 & & & \\
\hline & SE4 & .531 & 23.296 & & & \\
\hline & SE5 & .473 & 20.314 & & & \\
\hline \multirow[t]{5}{*}{ PO } & PO1 & .480 & 20.873 & \multirow[t]{5}{*}{.697} & \multirow[t]{5}{*}{.675} & .295 \\
\hline & $\mathrm{PO} 2$ & .572 & 25.814 & & & \\
\hline & PO3 & .499 & 21.846 & & & \\
\hline & PO4 & .612 & 28.077 & & & \\
\hline & PO5 & .543 & 24.195 & & & \\
\hline $\mathrm{AC}$ & $\mathrm{ACl}$ & .681 & 32.486 & .712 & .698 & .320 \\
\hline & $\mathrm{AC} 2$ & .506 & 22.275 & & & \\
\hline & $\mathrm{AC} 3$ & .622 & 28.765 & & & \\
\hline & $\mathrm{AC} 4$ & .511 & 22.552 & & & \\
\hline & $\mathrm{AC} 5$ & .481 & 20.976 & & & \\
\hline $\mathrm{HE}$ & HE1 & .596 & 26.800 & .656 & .508 & .341 \\
\hline & HE2 & .571 & 25.421 & & & \\
\hline ST & ST1 & .564 & 25.133 & .712 & .647 & .380 \\
\hline & ST2 & .631 & 28.919 & & & \\
\hline & ST3 & .651 & 30.124 & & & \\
\hline SD & SD1 & .545 & 23.736 & .583 & .598 & .241 \\
\hline & SD2 & .623 & 27.993 & & & \\
\hline & SD3 & .377 & 15.593 & & & \\
\hline & SD4 & .550 & 23.997 & & & \\
\hline & SD5 & .278 & 11.250 & & & \\
\hline Model Fit Indices & $\begin{array}{l}\chi^{2}=7023.88 \\
\text { SRMR }=.06 \\
\text { RMSEA }=. \\
\text { AIC }=7195 .\end{array}$ & $\begin{array}{l}000), \mathrm{df}=860, \chi^{2} / \mathrm{df}=8.1 \\
\mathrm{I}=.829, \mathrm{AGFI}=.812, \mathrm{C} \\
\% \mathrm{CI} \text { of } .060 \text { to } .063] \\
\mathrm{FI}=.719\end{array}$ & & & & \\
\hline
\end{tabular}

Note. CR, Construct Reliability; AVE, Average Variance Extracted; $\alpha$, Cronbach's alpha; -1, opposed to my values; 7 , of supreme importance. 
the Swiss sample and $26(58 \%)$ in the French sample lack discriminant validity. Furthermore, all 10 pairs of adjacent value types lack discriminant validity for both samples.

\section{Conclusion}

The objective of the present research is not to question the conceptual soundness of Schwartz's theory of human values. Our argument is that the SVS scale as a psychometric instrument should be further refined. In this article, the quasi-circumplex structure and the psychometric properties of SVS were tested using exploratory and confirmatory statistical approaches. A circumplex structure should meet three criteria: (1) differences among variables should be reducible to differences in two dimensions, (2) all variables should have equal projections, and (3) discretely measured variables should be uniformly distributed along a circle. In the case of a quasi-circumplex structure, the last criteria is relaxed. Following SVS research tradition, we started our analysis by using MDS, showing relatively good graphical display but rather unsatisfactory fit indices.

Because MDS does not allow us to formally test the quasi-circumplex structure of SVS, this first analysis was complemented with CIRCUM, a confirmatory technique specifically developed to test circumplex structures. Three different models were tested: an equal spacing-equal communalities model, an unequal spacing-equal communalities model, and an unequal spacing-unequal communalities model. Of the three models, only the unequally spaced-unequal communalities model came closer to acceptable levels of fit. However, none of the conditions for a circumplex structure was met. Because CIRCUM cannot test the circumplex structure for the latent variables together with the simple factorial structure of the manifest variables, constrained confirmatory factor analyses were conducted. Three different models were tested: two empirical circulant models based on different reference matrices and a quasi-circumplex model. None of these models comes close to an acceptable level of fit. In addition, fit indices are likely to decrease and reach unacceptable levels when nesting such a measurement model into a structural model (Anderson \& Gerbing, 1988; Fornell \& Yi, 1992). Finally, the reliability of the measures as well as their construct and discriminant validity were also tested. Results show that the measures have low levels of reliability and weak construct and discriminant validity, resulting from multicollinearity between value types. Thus, the present findings show that while exploratory approaches to test SVS quasi-circumplex structure provide acceptable results, confirmatory tests provide weak support.

As stated by Grewal et al. (2004), nothing can replace good quality measures and researchers should make every attempt to use reliable and valid measures of well identified constructs. Several factors could be the cause of the weak results of this study and identifying them may, therefore, provide the opportunity to improve the SVS scale: First, the number of value types (10) is probably too large to ensure discriminant validity. In a 10 dimension-circumplex model, correlation between adjacent value types is at least .60, which is high. Grewal et al. (2004) demonstrated that when multicollinearity is high (correlations between .60 and .80), Type II error levels can be substantial (greater than $50 \%$ and frequently above $80 \%$ ) when construct reliability is weak (.70 or lower). Further research is necessary to investigate the possibility of reducing the number of values without too much loss of substance. 
A second related issue is the reliability of the value items. The number of items measuring the 10 values ranges from 2 for Hedonism ${ }^{9}$ to 9 for Universalism and Benevolence, raising reliability and discriminant validity issues. Indeed, researchers have suggested that the circumplex structure can be distorted when unbalanced numbers of items are used to represent different regions on the circle (e.g., Feldman Barrett \& Russell, 1998; Russell \& Carroll, 1999). Several value items have weak loadings on their value dimensions, others have important cross-loadings, which amplify the problem of multicollinearity. This reliability issue may also be exacerbated by the length of the SVS instrument (Bouckenooghe, Buelens, Fontaine, \& Vanderheyden, 2005; Stern, Dietz, \& Guagnano, 1998; Van den Broeck, Vanderheyden, \& Cools, 2003). When integrated into a survey, the total number of items may easily reach 100 (Burroughs \& Rindfleisch, 2002), resulting in respondent fatigue. A shorter scale with more focused items should help reduce response biases produced by respondent fatigue and carelessness (Hinkin, 1995). Schwartz et al. (2001) also acknowledge that the SVS may be psychologically overly demanding for some respondents, which may result in reliability issues.

A model with 8 values (for instance by combining Tradition and Conformity and deleting Hedonism) would reduce the correlation between adjacent values and ensure discriminant validity (assuming an acceptable level of construct reliability) by significantly reducing multicollinearity. Another track for improving SVS is to use a secondorder CFA model with higher-order dimensions such as Self-enhancement/Self-transcendence (SE-ST) and Openness-to-change/Conservation (OC-CO) as suggested by Schwartz and Sagiv (1995) and Steenkamp et al. (1999). Value types as first-order dimensions relate to higher-order dimensions, that is, Power and Achievement to SE, Universalism and Benevolence to ST, Self-direction and Stimulation to OC, Conformitytradition and Security to CO. Such an improved measurement tool should provide better foundations for the testing of the circumplex structure of human values. The need for improvement was confirmed in the past and a few attempts have been made. Portrait Value Questionnaire (PVQ; Schwartz et al., 2001) and Personal Striving Value Survey (PSVS; Oishi et al., 1998) are, in this matter, already an improvement. However, further research is still needed to test the circumplex structure of human values as measured by these new instruments.

Finally, an important validity criterion for a scale is nomological validity (Brunsø et al., 2004; Cronbach \& Meehl, 1955; Gurtman, 1992). The predictive validity of SVS has already been assessed in several studies. However, given the potential presence of unstable parameter estimates resulting from multicollinearity (Grewal et al., 2004; Jagpal, 1982; Marsh et al., 2004a), new tests are necessary.

\section{Acknowledgments}

The authors thank Dominique Marguerat, John Antonakis, Brian den Ouden, and Alain de Beuckelaer for their inspiring comments on previous versions of the paper.

\footnotetext{
9 A third item Self-indulgence has recently been added to Hedonism in the latest version of the SVS (see Schwartz \& Boehnke, 2004; Schwartz et al., 2001; Spini, 2003).
} 


\section{References}

Acton, G. S., \& Revelle, W. (2002). Interpersonal personality measures show circumplex structure based on new psychometric criteria. Journal of Personality Assessment, 79(3), 456-481.

Anderson, J. C., \& Gerbing, D. W. (1984). The effect of sampling error on convergence, improper solutions, and goodness-of-fit indices for maximum likelihood confirmatory factor analysis. Psychometrika, 49(2), $155-173$.

Anderson, J. C., \& Gerbing, D. W. (1988). Structural equation modeling in practice: a review and recommended two-step approach. Psychological Bulletin, 103(3), 411-423.

Arbuckle, J. L., \& Wothke, W. (1999). Amos 4.0 user's guide. Chicago: SmallWaters.

Bagozzi, R. P., \& Edwards, J. R. (1998). A general approach for representing constructs in organizational research. Organizational Research Methods, 1(1), 45-87.

Bagozzi, R. P., \& Yi, Y. (1988). On the evaluation of structural equation models. Journal of the Academy of Marketing Science, 16(1), 74-94.

Bardi, A., \& Schwartz, S. H. (2003). Values and behavior: strength and structure of relations. Personality and Social Psychology Bulletin, 29(10), 1207-1220.

Belsley, D. A. (1991). Conditioning diagnostics: collinearity and weak data in regression. New York: Wiley.

Belsley, D. A., Kuh, E., \& Welsch, R. E. (1980). Regression diagnostics: Identifying influential data and sources of collinearity. New York: Wiley.

Ben Slimane, L., El Akremi, A., \& Touzani, M. (2002). Les domaines motivationnels de l'inventaire des valeurs de Schwartz: Une analyse confirmatoire. Deuxièmes Journées de la Recherche en Sciences de Gestion, February.

Bentler, P. M. (1990). Comparative fit indexes in structural models. Psychological Bulletin, 107(2), $238-246$.

Bentler, P. M., \& Bonett, D. G. (1980). Significance tests and goodness-of-fit in the analysis of covariance structures. Psychological Bulletin, 88(3), 588-606.

Borg, I., \& Lingoes, J. C. (1987). Multidimensional similarity structure analysis. New York: Springer-Verlag.

Bouckenooghe, D., Buelens, M., Fontaine, J., \& Vanderheyden, L. (2005). The prediction of stress by values and value conflict. Journal of Psychology, 139(4), 369-382.

Breivik, E., \& Olsson, U. H. (2001). Adding variables to improve fit: the effect of model size on fit assessment in LISREL. In R. Cudeck, S. du Toit, \& D. Sörbom (Eds.), Structural equation modeling: Present and future (pp. 169-194). Lincolnhood (IL): SSI-Scientific Software International.

Browne, M. W. (1992). Circumplex models for correlation matrices. Psychometrika, 57(4), 469-497.

Browne, M. W., \& Cudeck, R. (1992). Alternative ways of assessing model fit. Sociological Methods and Research, 21(2), 230-258.

Browne, M. W., \& Shapiro, A. (1988). Robustness of normal theory methods in the analysis of linear latent variate models. British Journal of Mathematical and Statistical Psychology, 41(2), 193-208.

Brunsø, K., Scholderer, J., \& Grunert, K. G. (2004). Testing relationships between values and food-related lifestyle: results from two European countries. Appetite, 43(2), 195-205.

Burroughs, J. E., \& Rindfleisch, A. (2002). Materialism and well-being: a conflicting value perspective. Journal of Consumer Research, 29(3), 348-370.

Byrne, B. M. (2001). Structural equation modeling with AMOS: Basic concepts, application, and programming. Mahwah, N.J: Lawrence Erlbaum Associates.

Cable, D. M., \& Edwards, J. R. (2004). Complementary and supplementary fit: a theoretical and empirical integration. Journal of Applied Psychology, 89(5), 822-834.

Carmines, E. G., \& McIver, J. P. (1981). Analyzing models with unobserved variables: analysis of covariance structures. In G. W. Bohrnstedt \& E. F. Borgatta (Eds.), Social measurement: Current issues (pp. 65-115). Beverly Hills: Sage.

Cronbach, L. J. (1951). Coefficient alpha and the internal structure of tests. Psychometrika, 16(September), 297334.

Cronbach, L. J., \& Meehl, P. E. (1955). Construct validity in psychological tests. Psychological Bulletin, 52(4), $281-302$.

Davison, M. L. (1983). Multidimensional scaling. New York: John Wiley and Sons.

Egri, C. P., \& Ralston, D. A. (2004). Generation cohorts and personal values: a comparison of China and the United States. Organization Science, 15(2), 210-220.

Ekkekakis, P., Hall, E. E., \& Petruzzello, S. J. (2005). Evaluation of the circumplex structure of the activation deactivation adjective check list before and after a short walk. Psychology of Sport and Exercise, 6(1), 83-101.

Fabrigar, L. R., Visser, P. S., \& Browne, M. W. (1997). Conceptual and methodological issues in testing the circumplex structure of data in personality and social psychology. Personality and Social Psychology Review, 1(3), 184-203. 
Fan, X., Thompson, B., \& Wang, L. (1999). Effects of sample size, estimation methods, and model specification on structural equation modeling fit indexes. Structural Equation Modeling, 6(1), 56-83.

Feather, N. T. (1995). Values, valences, and choice: the influence of values on the perceived attractiveness and choice of alternatives. Journal of Personality and Social Psychology, 68(July), 1135-1151.

Feldman Barrett, L., \& Russell, J. A. (1998). Independence and bipolarity in the structure of affect. Journal of Personality and Social Psychology, 74(4), 967-984.

Fornell, C., \& Larcker, D. F. (1981). Evaluating structural equation models with unobserved variables and measurement error. Journal of Marketing Research, 18(February), 39-50.

Fornell, C., \& Yi, Y. (1992). Assumptions of the two-step approach to latent variable modeling. Sociological Methods and Research, 20(3), 291-320.

Gaines, S., Jr., Panter, A. T., Lyde, M. D., Steers, W. N., Rusbult, C. E., Cox, C. L., et al. (1997). Evaluating the circumplexity of interpersonal traits and the manifestation of interpersonal traits in interpersonal trust. Journal of Personality and Social Psychology, 73(3), 610-623.

Grewal, R., Cote, J. A., \& Baumgartner, H. (2004). Multicollinearity and measurement error in structural equation models: implications for theory testing. Marketing Science, 23(4), 519-529.

Grunert, S. C., \& Juhl, H. J. (1995). Values, environmental attitudes, and buying of organic foods. Journal of Economic Psychology, 16(1), 39-62.

Gurtman, M. B. (1992). Construct validity of interpersonal personality measures: the interpersonal circumplex as a nomological net. Journal of Personality and Social Psychology, 63(1), 105-118.

Gurtman, M. B. (1993). Constructing personality tests to meet a structural criterion: application of the interpersonal circumplex. Journal of Personality, 61(2), 237-263.

Gurtman, M. B. (1994). The circumplex as a tool for studying normal and abnormal personality: a methodological primer. In S. Strack \& M. Lorr (Eds.), Differentiating normal and abnormal personality (pp. 243-263). New York: Springer.

Gurtman, M. B. (2001). Interpersonal complementarity: Integrating interpersonal measurement with interpersonal models. Journal of Counseling Psychology, 48(1), 97-110.

Gurtman, M. B., \& Pincus, A. L. (2000). Interpersonal adjective scales: confirmation of circumplex structure from multiple perspectives. Personality and Social Psychology Bulletin, 26(3), 374-384.

Guttman, L. A. (1954). A new approach to factor analysis: the radex. In P. F. Lazarsfel (Ed.), Mathematical thinking in the social sciences (pp. 258-348). Glencoe, IL: Free Press.

Hinkin, T. R. (1995). A review of scale development practices in the study of organizations. Journal of Management, 21(5), 967-988.

Hu, L., \& Bentler, P. M. (1998). Fit indices in covariance structure modeling: sensitivity to underparameterized model specification. Psychological Methods, 3(4), 424 453.

Hu, L., \& Bentler, P. M. (1999). Cutoff criteria for fit indexes in covariance structure analysis: conventional criteria versus new alternatives. Structural Equation Modeling, 6(1), 1-55.

Jagpal, H. S. (1982). Multicollinearity in structural equation models unobservable variables. Journal of Marketing Research, 19(November), 431-439.

Jöreskog, K. G. (1971). Statistical analysis of sets of congeneric tests. Psychometrika, 36(2), 109-133.

Jöreskog, K. G. (1974). Analyzing psychological data by structural analysis of covariance matrices. In D. H. Krantz, R. C. Atkinson, R. D. Luce, \& P. Suppes (Eds.), Contemporary developments in mathematical psychology (Vol. 2, pp. 1-56). San Francisco, CA: S. H. Freeman.

Jöreskog, K. G. (1978). Structural analysis of covariance and correlation matrices. Psychometrika, 43(4), 443-477.

Jöreskog, K. G., \& Sörbom, D. (1986). Analysis of linear structural relationships by the method of maximum likelihood. Mooresville, IN: Scientific Software.

Jöreskog, K. G., \& Sörbom, D. (1989). LISREL 7: A guide to the program and applications (2nd ed.). Chicago: SPSS

Kenny, D. A., \& McCoach, D. B. (2003). Effect of the number of variables on measures of fit in structural equation modeling. Structural Equation Modeling, 10(3), 333-351.

Kozan, M. K., \& Ergin, C. (1999). The influence of intra-cultural value differences on conflict management practices. International Journal of Conflict Management, 10(3), 249-267.

Kruskal, J. B. (1964). Multidimensional scaling by optimising goodness of fit to a nonmetric hypothesis. Psychometrika, 29(March), 1-27.

Larsen, R. J., \& Diener, E. (1992). Promises and problems with the circumplex model of emotions. In M. S. Clark (Ed.), Review of Personality and Social Psychology (13, pp. 25-59). Newbury Parck, CA: Sage.

Lindeman, M., \& Verkasalo, M. (2005). Measuring values with the short Schwartz's value survey. Journal of Personality Assessment, 85(2), 170-178. 
Lingoes, J. C. (1977). Geometric representations of relational data. Ann Arbor, MI: Mathesis.

Lingoes, J. C. (1981). Testing regional hypotheses in multidimensional scaling. In I. Borg (Ed.), Multidimensional data representations: When and why (pp. 280-310). Ann Arbor, MI: Mathesis.

MacCallum, R. C., \& Austin, J. T. (2000). Applications of structural equation modeling in psychological research. Annual Review of Psychology, 51, 201-226.

Maiti, S. S., \& Mukherjee, B. N. (1990). A note of distributional properties of the Jöreskog-Sörbom fit indices. Psychometrika, 55(4), 721-726.

Marsh, H. W., Dowson, M., Pietsch, J., \& Walker, R. (2004a). Why multicollinearity matters: a reexamination of relations between self-efficacy, self-concept, and achievement. Journal of Educational Psychology, 96(3), 518522.

Marsh, H. W., Hau, K.-T., \& Wen, Z. (2004b). In search of the golden rules: comment on hypothesis-testing approaches to setting cutoff values for fit indexes and dangers in overgeneralizing Hu and Bentler's (1999) findings. Structural Equation Modeling, 11(3), 230-341.

McDonald, R. P., \& Ho, M.-H. R. (2002). Principle and practice in reporting structural equation analyses. Psychological Methods, 7(1), 64-82.

McQuitty, S. (1997). Effects of employing ridge regression in structural equation models. Structural Equation Modeling, 4(3), 244-252.

Munson, J. M., \& McIntyre, S. H. (1979). Developing practical procedures for the measurement of personal values in cross-cultural marketing. Journal of Marketing Research, 16(February), 48-52.

Nunnally, J. C. (1978). Psychometric theory (second ed.). New York: McGraw-Hill.

Odin, Y., Vinais, J. Y., \& Valette-Florence, P. (1996). Analyse confirmatoire des domaines motivationnels de Schwartz : Une application au domaine des médias. Actes du Congrès de l'AFM, Université de Poitiers, 12, 125-138.

Oishi, S., Schimmack, U., Diener, E., \& Suh, E. M. (1998). The measurement of values and individualism-collectivism. Personality and Social Psychology Bulletin, 24(11), 1177-1189.

Olver, J. M., \& Mooradian, T. A. (2003). Personality traits and personal values: a conceptual and empirical integration. Personality and Individual Differences, 35(1), 109-125.

Pincus, A. L., Gurtman, M. B., \& Ruiz, M. A. (1998). Structural analysis of social behavior (SASB): circumplex analyses and structural relations with the interpersonal circle and the five-factor model of personality. Journal of Personality and Social Psychology, 74(6), 1629-1645.

Ping, R. A., Jr. (2004). On assuring valid measures for theoretical models using survey data. Journal of Business Research, 57(2), 125-141.

Ralston, D. A., Egri, C. P., Stewart, S., Terpstra, R. H., \& Yu, K. (1999). Doing business in the 21st century with the new generation of Chinese managers: a study of generational shifts in work values in China. Journal of International Business Studies, 30(2), 415-427.

Remington, N. A., Fabrigar, L. R., \& Visser, P. S. (2000). Reexamining the circumplex model of affect. Journal of Personality and Social Psychology, 79(2), 286-300.

Robinson, J. P., Shaver, P. R., \& Wrightsman, L. S. (1991). Criteria for scale selection and evaluation. In J. P. Robinson, P. R. Shaver, \& L. S. Wrightsman (Eds.), Measures of personality and social psychological attitudes (pp. 1-16). San Diego, CA: Academic Press.

Rokeach, M. (1973). The nature of human values. New York: The Free Press.

Russell, J. A., \& Carroll, J. M. (1999). On the bipolarity of positive and negative affect. Psychological Bulletin, 125(1), 3-30.

Schiffman, S. S., Reynolds, M. L., \& Young, F. W. (1981). Introduction to multidimensional scaling: Theory, methods and applications. New York: Academic Press.

Schultz, P. W., Gouveia, V. V., Cameron, L. D., Tankha, G., Schmuck, P., \& Franek, M. (2005). Values and their relationship to environmental concern and conservation behavior. Journal of Cross-Cultural Psychology, 36(4), 457-475.

Schwartz, S. H. (1992). Universals in the content and structure of values: theoretical advances and empirical tests in 20 countries. In M. P. Zonna (Ed.), Advances in experimental social psychology (pp. 1-66). San Diego, CA: Academic Press.

Schwartz, S. H. (1994). Are there universal aspects in the structure and contents of human values? Journal of Social Issues, 50(4), 19-45.

Schwartz, S. H., \& Bilsky, W. (1987). Toward a universal psychological structure of human values. Journal of Personality and Social Psychology, 53(3), 550-562.

Schwartz, S. H., \& Bilsky, W. (1990). Toward a theory of the universal structure and content of values: extensions and cross-cultural replications. Journal of Personality and Social Psychology, 58(5), 878-891. 
Schwartz, S. H., \& Boehnke, K. (2004). Evaluating the structure of human values with confirmatory factor analysis. Journal of Research in Personality, 38(3), 230-255.

Schwartz, S. H., Melech, G., Lehmann, A., Burgess, S., Harris, M., \& Owens, V. (2001). Extending the cross-cultural validity of the theory of basic human values with a different method of measurement. Journal of CrossCultural Psychology, 32(5), 519-542.

Schwartz, S. H., \& Sagiv, L. (1995). Identifying culture-specifics in the content and structure of values. Journal of Cross-Cultural Psychology, 26(January), 92-116.

Spini, D. (2003). Measurement equivalence of 10 value types from the Schwartz value survey across 21 countries. Journal of Cross-Cultural Psychology, 34(1), 3-23.

Spini, D., \& Doise, W. (1998). Organizing principles of involvement in human rights and their social anchoring in value priorities. European Journal of Social Psychology, 28(4), 603-622.

Steenkamp, J.-B. E. M., \& Baumgartner, H. (1998). Assessing measurement invariance in cross-national consumer research. Journal of Consumer Research, 25(1), 78-90.

Steenkamp, J.-B. E. M., ter Hofstede, F., \& Wedel, M. (1999). A cross-national investigation into the individual and national cultural antecedents of consumer innovativeness. Journal of Marketing, 63(April), 55-69.

Steiger, J. H., \& Lind, J. C. (1980). Statistically-based tests for the number of common factors. Paper presented at the Annual Spring Meeting of the Psychometric Society, Iowa City, IA.

Stern, P., Dietz, T., \& Guagnano, G. (1998). A brief inventory of values. Educational and Psychological Measurement, 58(6), 984-1001.

Strack, S., Choca, J. P., \& Gurtman, M. B. (2001). Circular structure of the MCMI-III personality disorder scales. Journal of Personality Disorders, 15(3), 263-274.

Thøgersen, J., \& Ölander, F. (2002). Human values and the emergence of a sustainable consumption pattern: a panel study. Journal of Economic Psychology, 23, 605-630.

Tracey, T. J. G. (2000). Analysis of circumplex models. In H. E. A. Tinsley \& S. D. Brown (Eds.), Handbook of applied multivariate statistics and mathematical modeling (pp. 641-664). San Diego, CA: Academic Press.

Tsai, R.-C., \& Böckenholt, U. (2002). Two-level linear paired comparison models: estimation and identifiability issues. Mathematical Social Sciences, 43(3), 429-449.

Tucker, L. R., \& Lewis, C. (1973). A reliability coefficient for maximum likelihood factor analysis. Psychometrika, $38(1), 1-10$.

Van den Broeck, H., Vanderheyden, K., \& Cools, E. (2003). Linking cognitive styles and values. Working paper series Vlerick Leuven Gent Management School.

Wagner, C. C., Kiesler, D. J., \& Schmidt, J. A. (1995). Assessing the interpersonal transaction cycle: convergence of action and reaction interpersonal circumplex measures. Journal of Personality and Social Psychology, 69(5), 938-949.

Wiggins, J. S., Steiger, J. H., \& Gaelick, L. (1981). Evaluating circumplexity in personality data. Multivariate Behavioral Research, 16(3), 263-289.

Wilson, M. S. (2005). A social-value analysis of postmaterialism. Journal of Social Psychology, 145(2), 209-224.

Wothke, W. (1993). Nonpositive definite matrices in structural modeling. In K. A. Bollen \& J. S. Long (Eds.), Testing structural equation models (pp. 256-293). San Diego, CA: Academic Press. 